\title{
Evolution of Longitudinal Resistance Performance of Granular Ballast Track with Durable Dynamic Reciprocated Changes
}

\author{
Jieling Xiao,, ${ }^{1,2}$ Hao Liu $\mathbb{D}^{1,2}$ Ping Wang, ${ }^{1,2}$ Ganzhong Liu, ${ }^{1,2}$ Jingmang $X u\left(\mathbb{D},{ }^{1,2}\right.$ and \\ Rong Chen $\mathbb{D}^{1,2}$ \\ ${ }^{1}$ MOE Key Laboratory of High-Speed Railway Engineering, Southwest Jiaotong University, Chengdu 610031, China \\ ${ }^{2}$ School of Civil Engineering, Southwest Jiaotong University, Chengdu 610031, China \\ Correspondence should be addressed to Hao Liu; liuhao@my.swjtu.edu.cn; Rong Chen; chenrong@home.swjtu.edu.cn
}

Received 10 November 2017; Revised 7 December 2017; Accepted 11 December 2017; Published 8 February 2018

Academic Editor: Aniello Riccio

Copyright (C) 2018 Jieling Xiao et al. This is an open access article distributed under the Creative Commons Attribution License, which permits unrestricted use, distribution, and reproduction in any medium, provided the original work is properly cited.

A full-scale test model with a distinct loading system is developed to analyze the dynamic change process of ballast beds under cyclic longitudinal reciprocated loading. The test analysis methodology accounts for the service performance, longitudinal resistances, and evolution trend of ballast beds under long-term loading. The analysis shows that the ballast resistancedisplacement curves under cyclic loading are a set of closed hysteretic curves, indicating obvious energy consumption. In particular, a granular ballast bed is subject to cyclic softening during the cyclic process and the ballast longitudinal resistances degenerate obviously. More particularly, the cyclic softening of a granular ballast bed is dependent on the dynamic disturbance amplitude-the higher the dynamic disturbance amplitude, the more severe the cyclic softening will become. Moreover, this methodology contributes to forming a foundation for an in-depth understanding of the dynamic service performance of ballast CWR tracks and of the stress deformation mechanism of continuously welded rail tracks.

\section{Introduction}

Ballast beds, characterized by a structural dependence, are solid and uneven structures composed of discrete particles of different sizes based on the gradation. Railway ballast bed structures have been adopted worldwide in view of their good elasticity, excellent damping capacity, strong water permeability, and easy maintenance [1-5]. Continuously welded rail (CWR) tracks have become standard modern track structures $[6,7]$. The ballast longitudinal and lateral resistance, which is closely related to line stability and rail creeping, is still a major research topic [8-10]. The longitudinal resistance values and evolution trend that directly affect the longitudinal line stability, rail bar design plans, rail creeping, and safe service of CWR tracks are of particular importance $[11,12]$.

The longitudinal load-bearing and force-transference mechanisms of ballast beds are highly complex because of the discreteness and composition of ballast track structures and the repeatability of loads $[13,14]$. In one aspect, the stress performance of ballast beds is related to the loading history; in another, the stacked state of granular ballast exhibits a high degree of randomness and its structure changes randomly. Taking CWR ballast tracks on a bridge as an example, because of the periodicity of temperature load, ballast beds are always subject to dynamic reciprocated changes yielding different displacement results because of the bridge-rail interaction $[15,16]$. The distribution of ballast resistance is characterized by discrete elements, randomness, and strong nonlinearity.

\section{Literature Review}

In recent years, ballast resistance has been studied based on experimental data and in accordance with statistics. Kerokoski performed field tests to measure the track resistance at a rail yard [14]. Le Pen and Powrie conducted a full-scale model test to quantify the relative contributions to the total sliding resistance of the sleeper base, crib, and shoulder $[17,18]$. Single-railroad tie pullout tests and track panel pullout tests were conducted on 1/5-scale models to evaluate 
the lateral resistance of railroad ties [19]. In addition, the numerical simulation of ballast track bed mechanical performance based on granular grains method has also progressed. Indraratna et al. presented the results of the effect of frequency on the permanent deformation and degradation behavior of ballast during cyclic loading [20]. Tutumluer et al. constructed ballast layers to investigate the ballast compaction, strength, and stability conditions before and after tamping [1]. Hollow cylinder tests were conducted to investigate the role of drainage conditions on the response of railway track foundation materials during cyclic loading [21].

The existing research findings mainly focus on vertical or transversal stability and do not cover all the aspects involved in the ballast response. Moreover, the ballast longitudinal resistance and its evolution trend under cyclic longitudinal changes are still unknown, which play an important role in the thermal buckling and stress deformation mechanism of a ballasted railway track. Consequently, it is not possible to use them as the basis for quantitative predictions of the ballast behavior in different scenarios. More particularly, the ballast longitudinal resistance-displacement curves are supposed as ideal hysteretic ones; their evolution characteristics of elasticity, plasticity, and energy consumption are neglected; and the evolution law of ballast longitudinal resistance under dynamic changes is still unknown, which play an important role in the thermal buckling and stress deformation mechanism of a ballasted railway track. Therefore, it is necessary to further analyze the hysteretic behaviors and evolution trend of ballast longitudinal resistance under cyclic loading.

\section{Research Objective and Scope}

In order to narrow the present knowledge gap, further experimental investigations integrated with those which have been carried out until now are needed. More particularly, a distinct loading program is necessary to characterize the ballast behavior subjected to dynamic reciprocated changes in track configurations since it allows reproduction of testing conditions that are very close to the service ones.

Based on the abovementioned discussion, this research activity aims at an in-depth understanding of the dynamic longitudinal resistance performance of ballast tracks and identifying the stress deformation mechanism of CWR tracks used under cyclic loading. A series of model tests investigated the ballast longitudinal resistance-displacement hysteretic curves and its evolution trend under cyclic longitudinal loading. More particularly, from a more practical point of view, the field tests about the ballast longitudinal resistance performance under long-term service conditions were carried out, and the following aspects obtained by some experimental results were reported and critically discussed:

(1) The ballast longitudinal resistance-displacement hysteretic curves under cyclic loading were obtained and analyzed.

(2) The ballast longitudinal resistance performance after dynamic reciprocated loading and its evolution law were investigated.
(3) The ballast longitudinal resistance performance under long-term service conditions were obtained through field tests.

(4) Images of the ballast surface are taken for observing and measuring ballast movement under longitudinal loading.

\section{Full-Scale Test Model}

Considering the complicated size effect and track panel interaction of ballast beds, full-scale track-panel-ballast bed models are more applicable for simulating on-site ballast bed structures [7]. The number of sleepers in the track frames is closely related to the resistance of the ballast bed and does not greatly influence the resistance change law $[2,7]$. Therefore, a track panel with six sleepers was selected as the test model. The intermediate four sleepers were used as the test objects, and the sleepers at each end were considered the model boundaries.

4.1. Outline of Full-Scale Track Model. The model track had a CHN60 rail, type-II fastener system, and type-III concrete sleepers with shoulders. The sleeper spacing was $0.6 \mathrm{~m}$. The section size of the ballast bed satisfied the requirements for a single line of ballast beds of a high-speed railway ballast track in China [22], as shown in Figure 1. The top width and thickness of the model ballast bed were $3.60 \mathrm{~m}$ and $0.35 \mathrm{~m}$, respectively. The top of the ballast bed was $40 \mathrm{~mm}$ lower than the rail support surface of the sleeper, and the slope of the ballast shoulder was $1: 1.75$. In addition, the piled ballast shoulder was $0.15 \mathrm{~m}$.

Ballast samples were prepared by layers under the conditions similar to the field according to ballast specifications. In the test model, all the particles are irregular clumped particles generated uniformly according to the sample of tests and diameters. The ballast bed was paved with Class I materials. Before paving, the ballast particle sizes were classified with a standard square plug gauge to ensure the gradation of the formed ballast met code requirements (Railway Ballast, TB/T 2140-2008) [23, 24]. The ballast material was crushed basalt stone, which was a commonly used ballast aggregate in the state of China. Its physical and durable attributes are shown in Table 1. The selected particle size distribution (PSD) for ballast was based on current industry practices (Standards China 2008) as shown in Figure 2. The Los Angeles abrasion (LAA) of the ballast particles was $23 \%$. The standard aggregate impact toughness (IP) was $97 \%$, the standard aggregate crushing value (CA) was $8 \%$, and the ballast aggregate crushing value $(\mathrm{CB})$ was $20 \%$. The compressive strength of stone powder specimen which refers to uniaxial compressive strength of the specimen was $0.3 \mathrm{MPa}$.

4.2. Loading Apparatus. The ballast track model was equipped with a distinct loading apparatus consisting of an actuator unit, a sensor unit, and a data collection unit, as depicted in Figure 3. The CF- $300 \mathrm{kN}$ precision power servo actuator, provided with a force or displacement control 


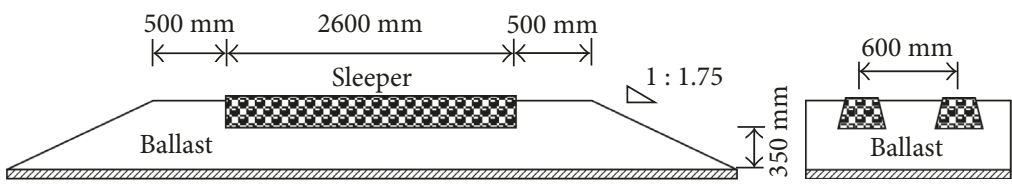

(a)

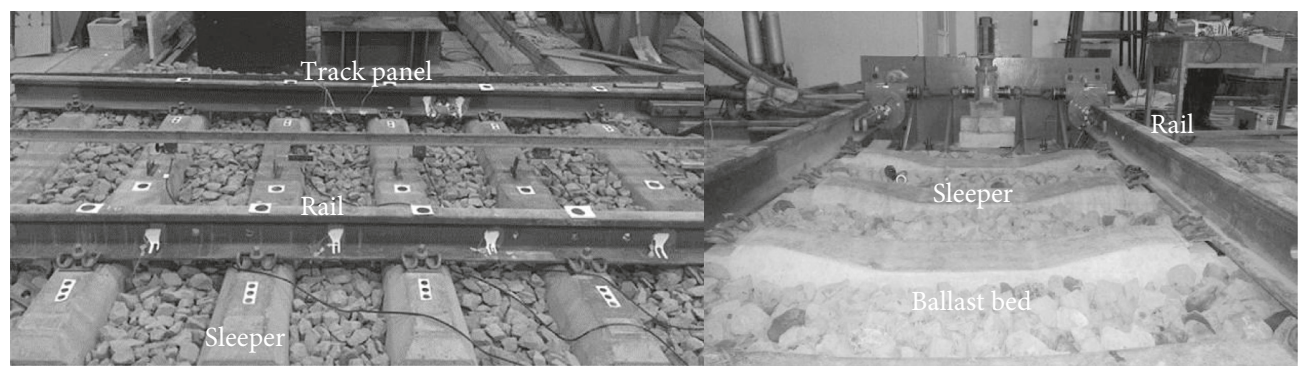

(b)

Figure 1: Outline of full-scale track model: (a) section size of the ballast bed and (b) model track panel.

TABle 1: Physical and durable attributes of Class I ballast materials.

\begin{tabular}{|c|c|c|}
\hline Parameters & Characteristics of test results & Recommendations by Standards China (2008) \\
\hline Abrasion and impact resistance & $\begin{array}{c}\text { Los Angeles abrasion, LAA (\%) } \\
\text { Standard aggregate impact toughness, IP (\%) } \\
\text { Wearable rigidity index, } K\end{array}$ & $\begin{array}{c}18<\text { LAA }<27 \\
95<\text { IP }<110 \\
18<K<27\end{array}$ \\
\hline Crushing resistance & $\begin{array}{l}\text { Standard aggregate crushing value (\%) } \\
\text { Ballast aggregate crushing value (\%) }\end{array}$ & $\begin{aligned} 8 & \leq \mathrm{CA}<9 \\
19 & \leq \mathrm{CB}<22\end{aligned}$ \\
\hline Water permeability & Stone powder specimen compressive strength $(\mathrm{MPa})$ & $<0.4$ \\
\hline Stability performance & Density $\left(\mathrm{g} / \mathrm{cm}^{3}\right)$ & $>2.55$ \\
\hline Particle shape & $\begin{array}{c}\text { Flakiness (\%) } \\
\text { Angularity index (\%) }\end{array}$ & $\begin{array}{l}<20 \\
<20\end{array}$ \\
\hline
\end{tabular}

function, was used as the actuator unit to perform the twoway synchronization control test and to control feedback through a servo drive system (Figure 3). The sensor unit consisted of a JXLY-LF spoke-type tension/pressure sensor (range: $\pm 300 \mathrm{kN}$; accuracy: $0.01 \mathrm{kN}$ ) and a CW-YB-2 displacement transducer (range: $\pm 50 \mathrm{~mm}$; accuracy: $0.01 \mathrm{~mm}$ ). A DHDAS dynamic signal analyzer was used as the data collection unit for real-time collection and recording.

The actuator unit of the loading apparatus used for the test loaded the track frame synchronously through the two rails. The sensor unit and data collection unit were used for collecting and recording the measured load and displacement values of the track panel. The dynamic displacement or force load output of the actuator unit could be realized through the servo feedback system and control center to simulate a stressed track panel subject to durable dynamic reciprocated changes for estimating the longitudinal resistance of the ballast bed.

4.3. Test Conditions. The track frame reciprocated motion caused by longitudinal rail forces is a main factor influencing the ballast stability on long-term service lines. In this test, a dynamic reciprocated load with the distinct loading system was exerted on the granular ballast bed via the fastener

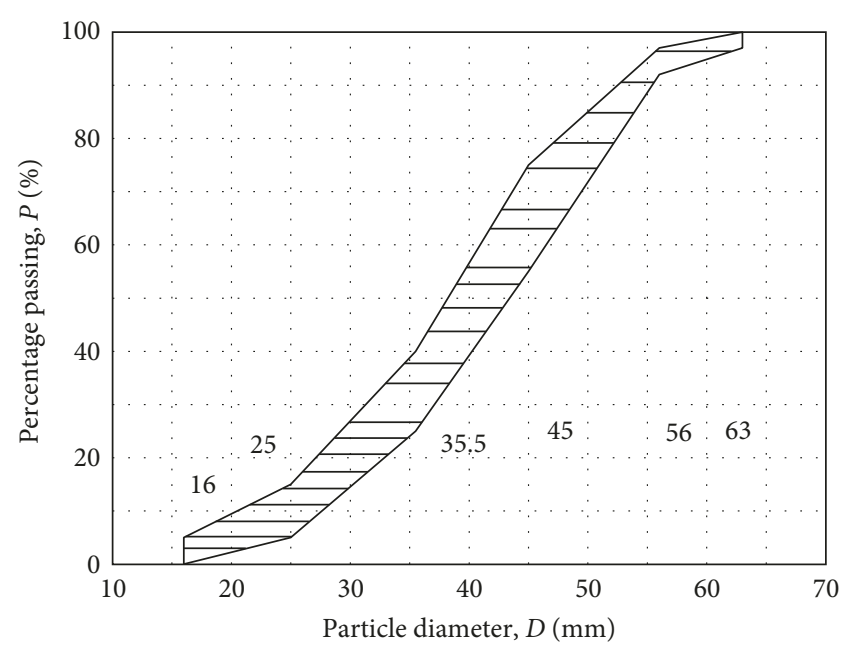

Figure 2: Ballast grain size distribution.

system and sleepers, and the influence of the track dynamic cyclic disturbance on the ballast longitudinal resistance was studied.

Temperature load is one of the main loads on CWR tracks, and its periodicity can subject the ballast within sleeper cribs to cyclic "equilibrium-transfer-redistribution" 


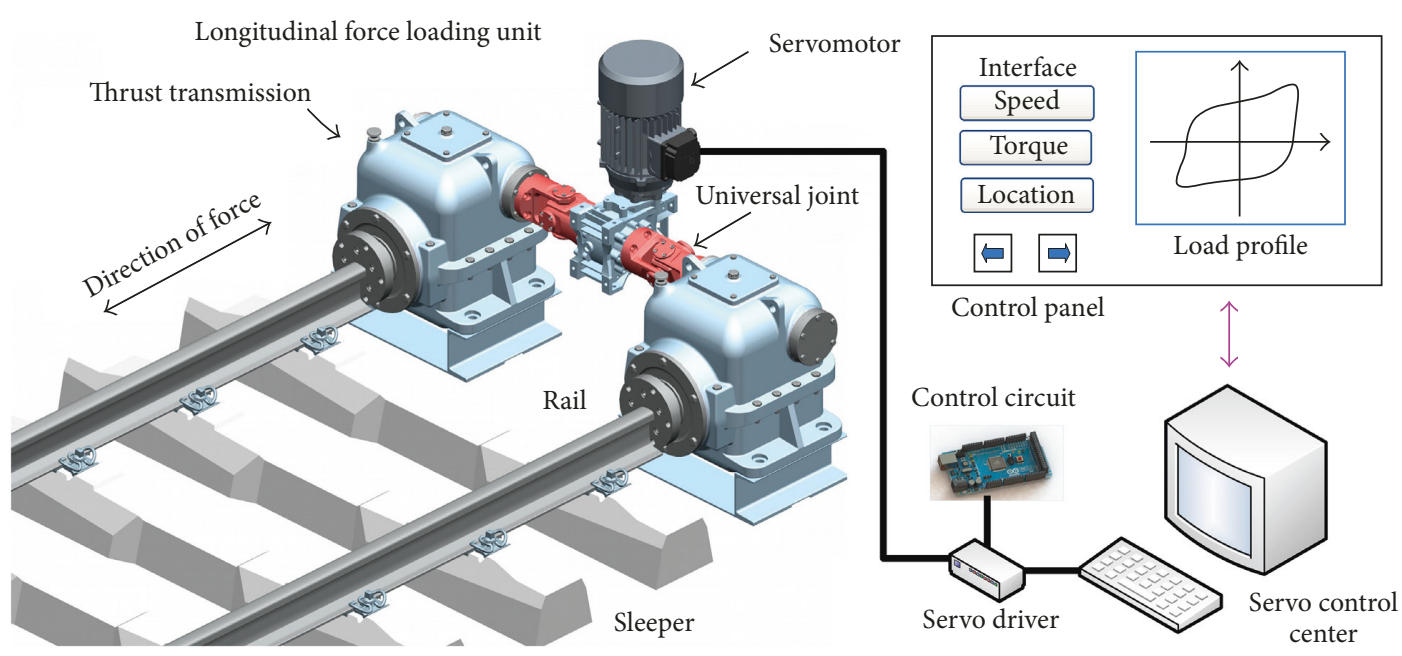

FIGURE 3: Schematic diagram of the loading apparatus.

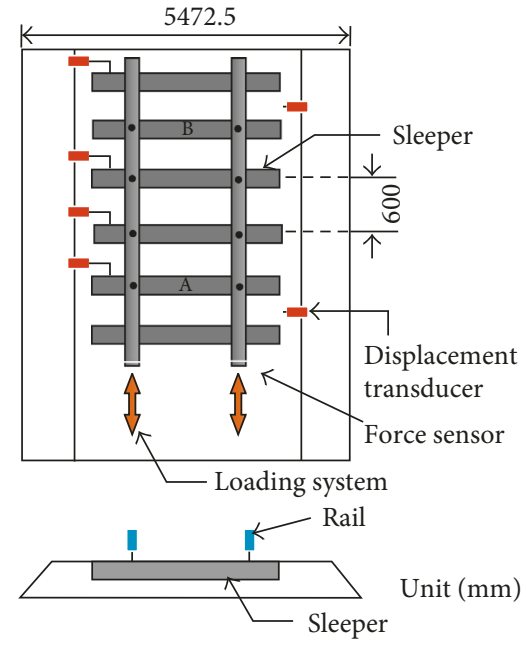

(a)

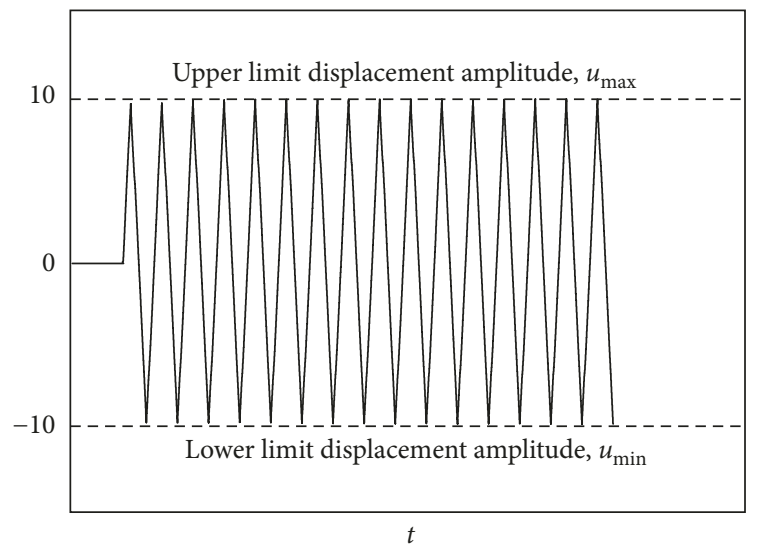

(b)

FIGURE 4: Outline of loading conditions: (a) arrangement of test model and (b) loading curve.

changes that in turn vary the degree of compaction and longitudinal resistance of the ballast beds. For the structure of CWR tracks, we take the CWR tracks on a simple bridge with a span of $64 \mathrm{~m}$ as an example. When the beam temperature changes by $30^{\circ} \mathrm{C}$, the maximum bridge expansion displacement is about $18 \mathrm{~mm}$, greater than $10 \mathrm{~mm}$. Therefore, different loading plans for cyclic displacement amplitudes, namely, low displacement amplitude $(4 \mathrm{~mm}$ and $6 \mathrm{~mm})$, medium displacement amplitude $(10 \mathrm{~mm})$, and high displacement amplitude $(20 \mathrm{~mm})$, were selected in the test in order to simulate the dynamic changes of ballast beds $[12,15]$. In particular, in order to simulate the slow change process of temperature load and ensure the stability of the load during the test, the longitudinal resistance performance of granular ballast bed was studied under quasi-static loading rate, and the cyclic triangular loading was adopted [13]. During the test, the loading rate remains constant and is changed slowly under the condition of lower frequency range. The loading rate $(1 \mathrm{~mm} / \mathrm{min})$ was constant during cyclic triangular wave loading (Figure 4).

\section{Discussion of Results}

5.1. Ballast Longitudinal Resistance under Dynamic Reciprocated Loading. The resistance of the ballast bed under variable displacement amplitudes during test loading was subject to obvious discreteness and nonlinearity, and its evolution law was closely related to the displacement amplitude. The longitudinal resistance and displacement hysteretic curves of the ballast bed under different displacement amplitudes are shown in Figure 5.

It can be seen from Figure 5 that the dynamic load $f$ and the corresponding dynamic displacement $u$ formed a hysteretic loop within a cycle. The resistance-displacement curves of the granular ballast bed obtained under cyclic loading were a set of closed and relatively stable hysteretic 


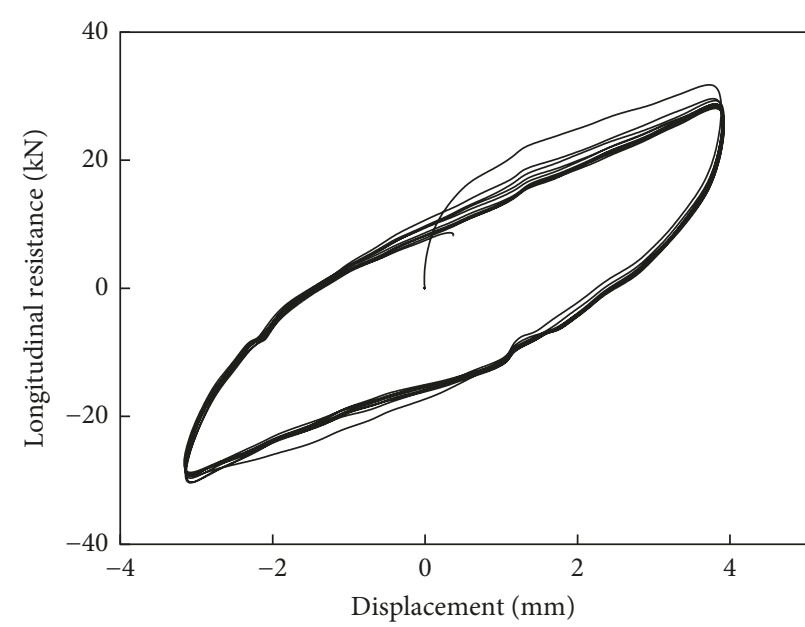

(a)

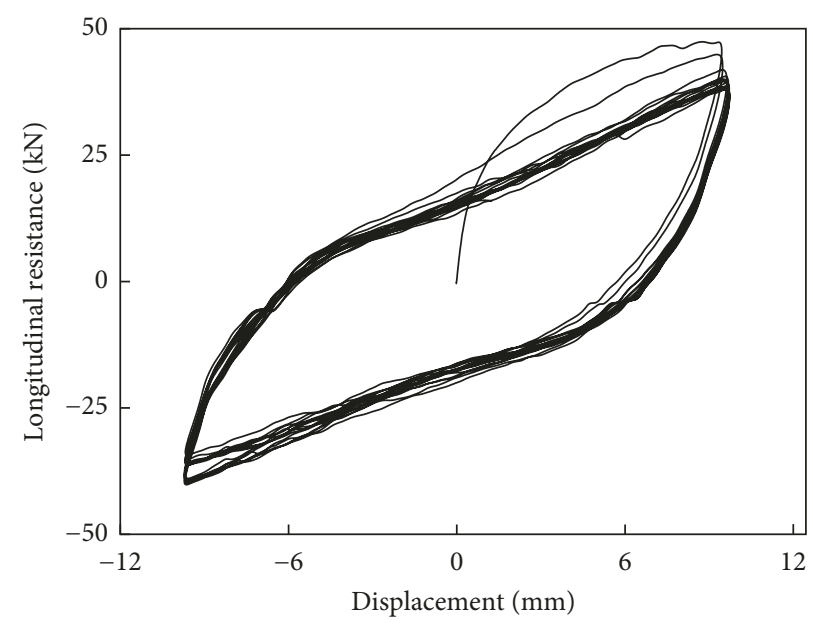

(c)

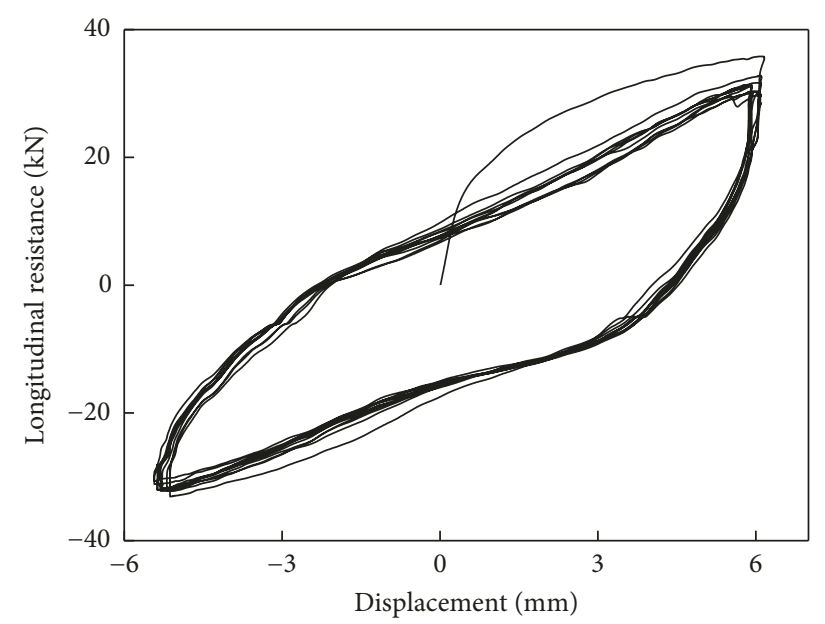

(b)

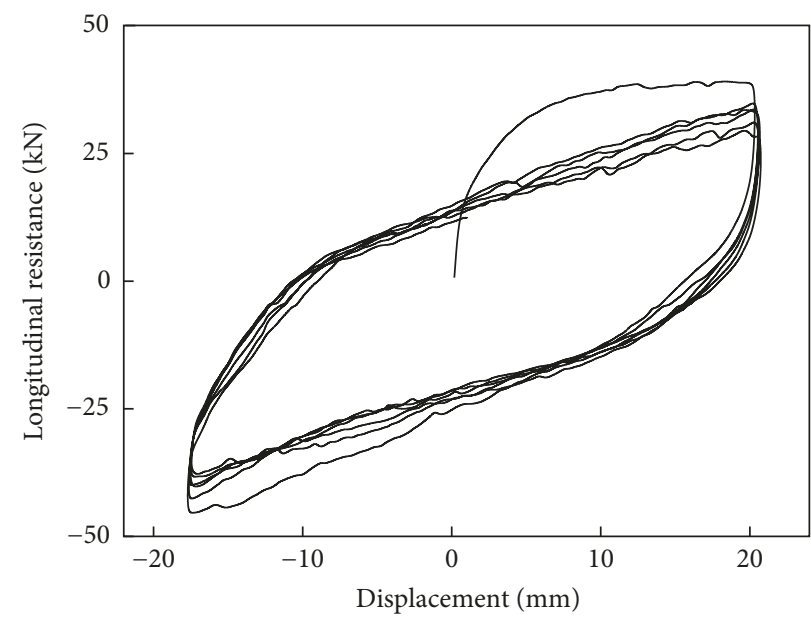

(d)

FIGURE 5: Resistance-displacement hysteretic curves of ballast bed under different displacement amplitudes: (a) $4 \mathrm{~mm}$, (b) $6 \mathrm{~mm}$, (c) $10 \mathrm{~mm}$, and (d) $20 \mathrm{~mm}$.

curves, indicating that the ballast bed was in a stable energy consumption state under cyclic loading. The resistancedisplacement curve under the initial load basically coincided with the unidirectional loading curve recorded in [7] and was different from the subsequent cyclic loading curves. For the subsequent cycle, the force-displacement curves are similar to each other from the second loading cycle onward, and the resistance of the ballast bed is subject to a stable hysteretic change.

When the dynamic disturbance amplitude is low, granular ballast beds tend toward stable cycling, the repeatability of hysteretic curves is good, the peak value is reliable, and the ballast beds are in a relatively stable elasticplastic state (Figure 5(a)). When the displacement amplitude reached $6 \mathrm{~mm}$ or higher, the hysteretic curves fluctuated and the resistance peak value changed within a narrow range (Figures 5(b)-5(d)). In particular, the test shows that when the ballast bed is disturbed under high longitudinal displacement, plastic flow will be produced in the ballast grains and the grain flow changes randomly. Moreover, the stability of the hysteretic curves decreases and the repeatability of the hysteretic curves is relatively poor. Hence, for the sake of safety, it is reasonable to control the quick relative longitudinal displacement of the ballast bed (taking DS899/59 as an example, the control of quick relative longitudinal displacement of the ballast bed should not exceed $4 \mathrm{~mm}$ ) [15].

In addition, based on the test results, granular ballast beds are subject to cyclic degeneration during dynamic reciprocated disturbance, including longitudinal bearing capacity degeneration and residual deformation increase (Figure 6).

As shown in Figure 6, the dynamic cyclic disturbance can significantly affect the ballast longitudinal resistance, which is significantly degenerated. That is, when the displacement reaches the ultimate value, the ultimate resistance value compared to the previous cycle will reduce during unloading. Furthermore, the residual deformation at the end of the unloading curve increases relative to the last residual 


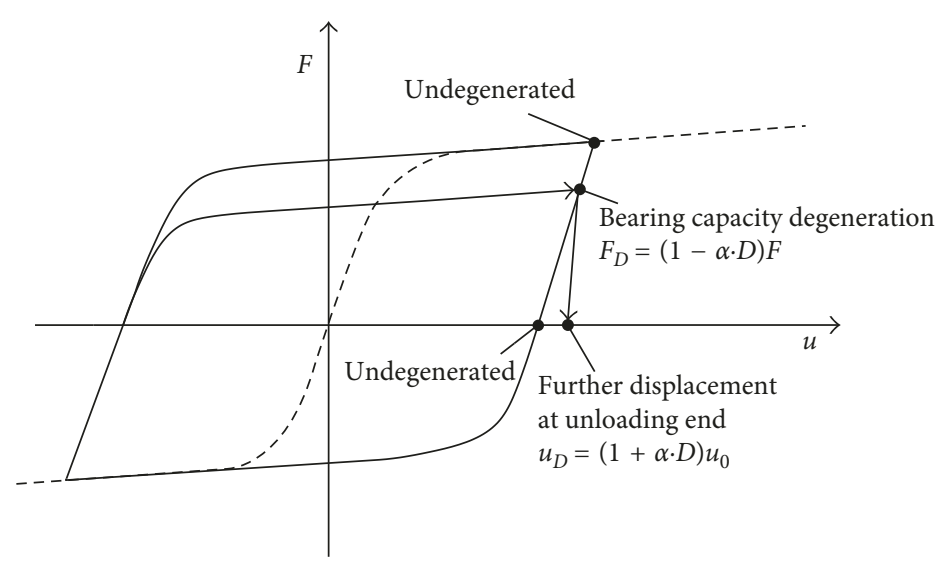

(a)

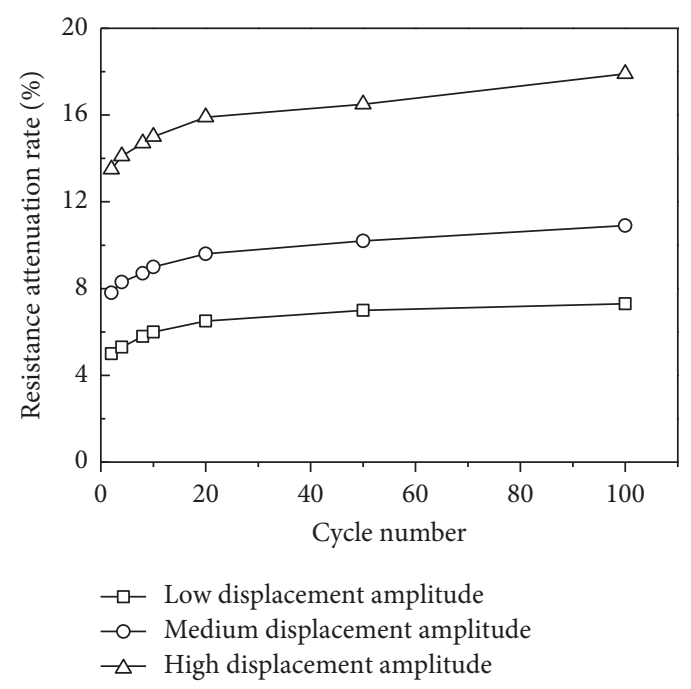

(b)

FiguRE 6: Ballast resistance performance subjected to durable dynamic reciprocated changes: (a) bearing capacity degeneration of granular ballast beds and (b) attenuation rate of ballast ultimate resistance.

deformation value. When the dynamic reciprocated displacement amplitude is high, the ballast bed is highly disturbed and the degeneration of the resistance under cyclic loading is more obvious.

\subsection{Evolution of Ballast Longitudinal Resistance after Dy-} namic Reciprocated Loading. Previous studies have shown that ballast resistance is affected mainly by the condition of the ballast around the sleeper cribs, sleeper ends, and at the bottom of the sleeper when a load is first applied and is then affected by the state of the ballast at the sleeper cribs with the increase in sleeper displacement. When the ballast bed was disturbed by dynamic reciprocated loading, ballast rigidity fell sharply around the sleeper cribs and sleeper ends, and the ballast resistance changes gradually. Therefore, the authors performed the test for ballast resistance after dynamic reciprocated loading and the evolution trend of ballast resistance was investigated, as shown in Figure 7.

As shown in Figure 7, when the ballast bed is disturbed under dynamic reciprocated loading, the ballast longitudinal resistance is degenerated; its degeneration law is closely related to the disturbance displacement amplitude. When the displacement amplitude is low (e.g., displacement amplitude $4 \mathrm{~mm}$ ), the ballast longitudinal resistance decreased within a narrow range and the difference is relatively small. However, when the displacement amplitude is high (e.g., displacement amplitude $20 \mathrm{~mm}$ ), the ballast bed entirely descends and plastic flow of the ballast is caused compared with the initial loading. Along with the increase in the sleeper longitudinal displacement, the ballast bed longitudinal resistance is subject to plastic deformation and the resistance degenerates (Figure 7(d)). After the dynamic reciprocated load is exerted 200 times, the attenuation rate of the ballast longitudinal resistance at the displacement of $2 \mathrm{~mm}$ is about $27 \%$ and the longitudinal bearing capacity of the ballast bed decreases obviously. Therefore, for ballast beds under long-term service, the attenuation of resistance transference capacity under dynamic reciprocated loading should be fully considered to avoid the decline of line stability caused by the degeneration of ballast longitudinal resistance. Although the different load cycles are applied in the test condition, the main purpose is to investigate the ballast resistance performance and its evolution trend under cyclic loading with different displacement amplitudes, and the experimental results show that the influence of displacement amplitude on ballast resistance performance is more obvious than the influence of the number of load cycles.

Ballast is a rather discontinuous medium, and it seems that the resistance behavior of the ballast bed under cyclic loading is mainly influenced by the movement of grains. Hence, based on particle image velocimetry (PIV) image identification technology, the motion law of ballast grains under longitudinal loading of track frames was analyzed $[13,17]$. Images of the ballast surface were taken using a digital camera for observing and measuring ballast movement during the tests [25], as shown in Figure 8. The digital camera was set above the ballast, and the image scales were approximately 3.5 pixels per millimeter for the $1,000 \mathrm{~mm}$ wide testing area. The technique is capable of providing a clear picture of overall movements, which can reflect the motion laws of ballast under longitudinal loading.

The test results show that when the sleepers move along in the longitudinal direction, the ballast grains show an irregular motion law. After loading, ballast grains will scatter and finally be transferred to a new equilibrium position. With a low displacement amplitude, the ballast grains in the sleeper cribs are in a relatively stable state under the longitudinal loading. The higher the cyclic displacement amplitude, the more obvious the disturbance to the ballast bed is and the more obvious the irregularity of the displacement and motion of the ballast grains will become. The ballast bed 


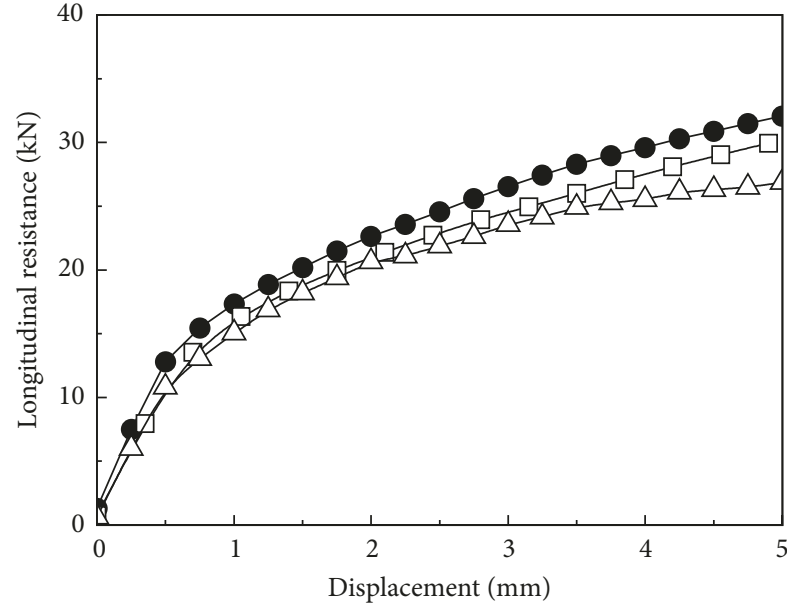

- No reciprocated loading

$\neg-100$ cycles

$\triangle 200$ cycles

(a)

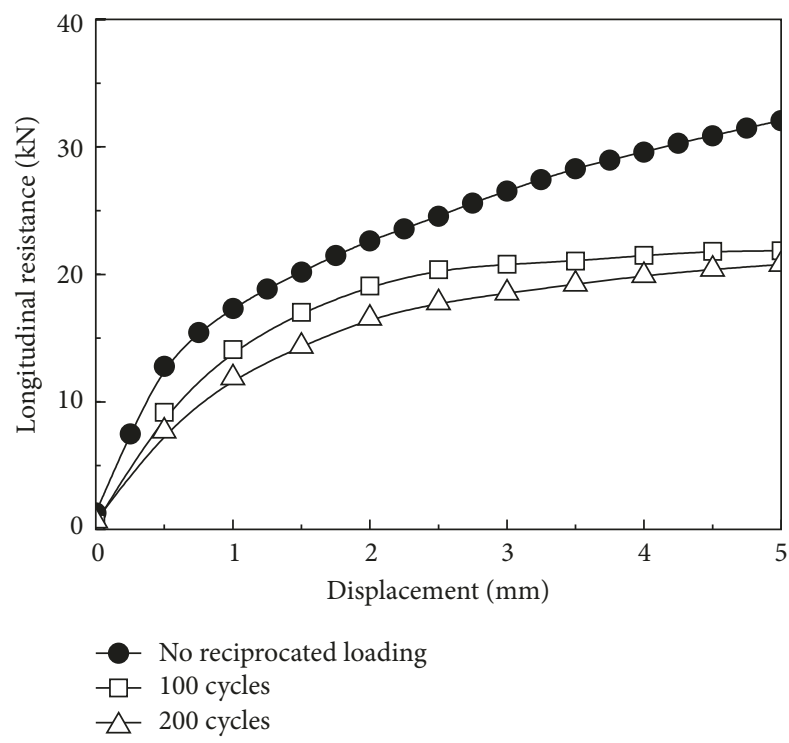

(c)

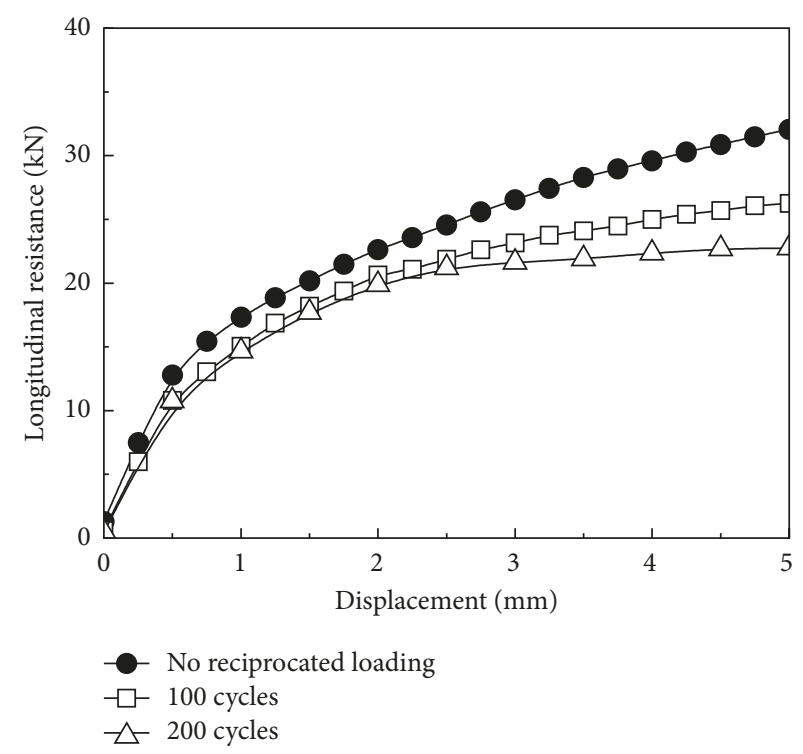

(b)

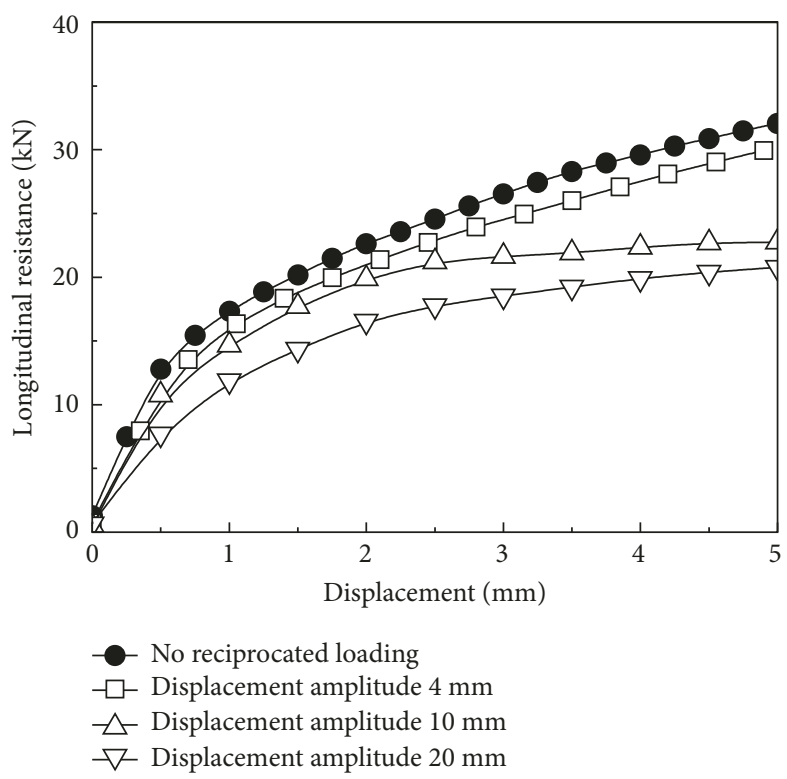

(d)

FiguRe 7: Ballast longitudinal resistance displacement curves: (a) displacement amplitude $4 \mathrm{~mm}$, (b) displacement amplitude $10 \mathrm{~mm}$, (c) displacement amplitude $20 \mathrm{~mm}$, and (d) relationship between ballast resistance and displacement.

becomes loose and is reconstructed, and this will cause degeneration of the ballast longitudinal resistance.

In addition, vehicle loads and maintenance activities dramatically decrease the ballast strength and stability by disturbing the consolidated ballast [26,27], which influences the resistance performance under cyclic loading. At present, this paper presents the preliminary results of long-term behavior of ballast without considering the influence of vehicle loads and maintenance activities.

5.3. Field Test. For CWR tracks on bridges, owing to the longitudinal bridge-track interaction, the ballast beds at bridge beam gaps are always subject to dynamic changes under cyclic temperature loading. To investigate the resistance performance and variation trend of granular ballast beds under long-term service conditions, the ballast resistance on a bridge was tested and some experimental results were reported and critically discussed.

The bridge was a $40+60+40 \mathrm{~m}$ concrete continuous beam bridge on the Chengdu outer-ring line, CHN60 rail, type-III concrete sleepers, and Class I ballast. Six testing points were set at the subgrade and bridge, respectively, including three points on the subgrade (SG1, SG2, and SG3) and three points on the bridge (LF, MF, and RF) (Figure 9). 


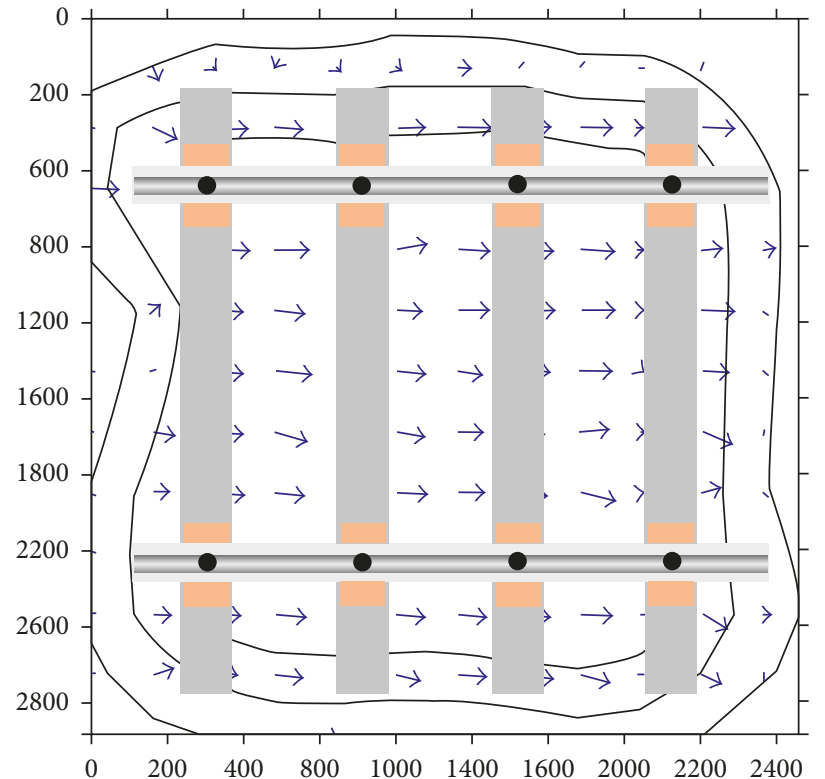

(a)

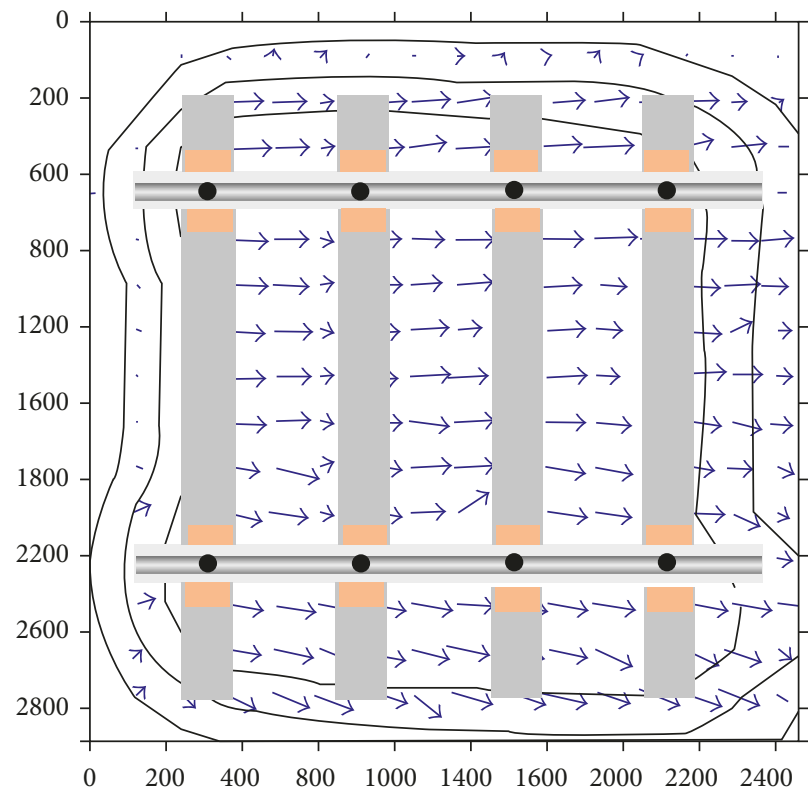

(c)

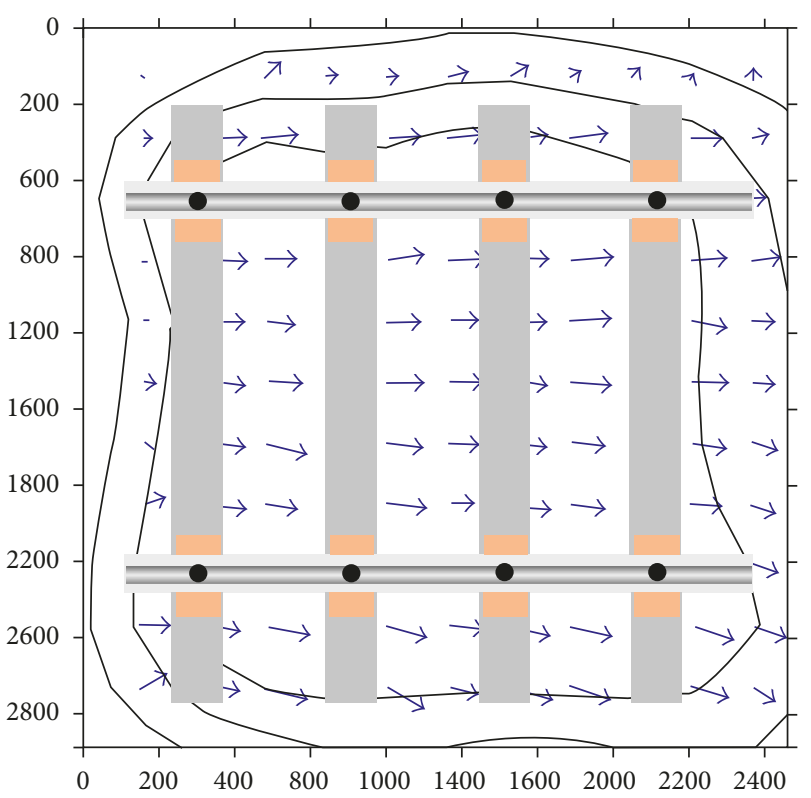

(b)

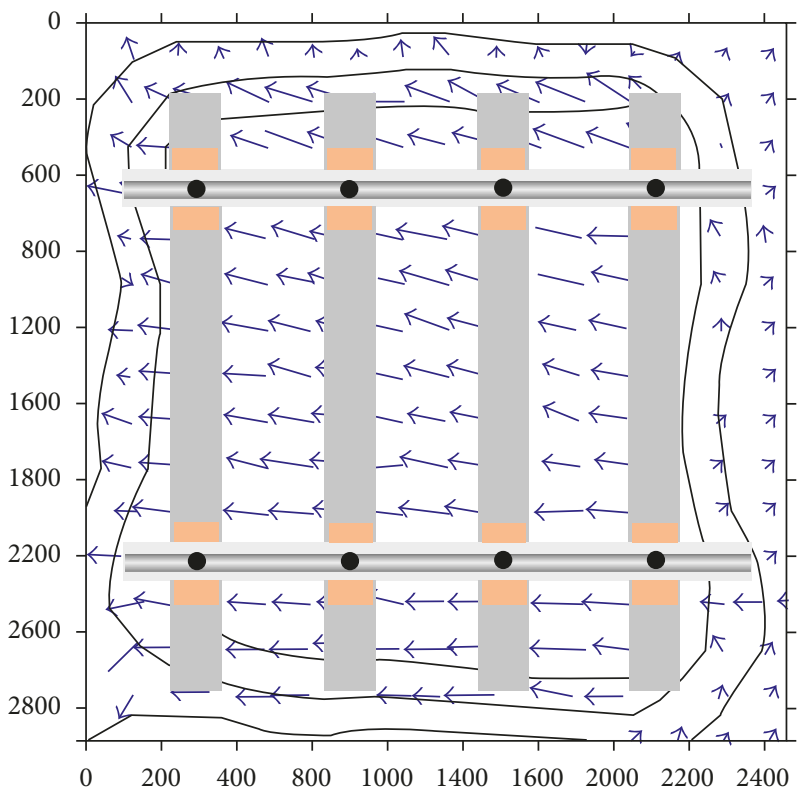

(d)

Figure 8: Motion of ballast grains under different displacement amplitudes: (a) $4 \mathrm{~mm}$, (b) $6 \mathrm{~mm}$, (c) $10 \mathrm{~mm}$, and (d) $20 \mathrm{~mm}$.

The ballast longitudinal resistance-displacement curves are shown in Figure 10.

In addition, Table 2 shows the representative ballast resistance values measured at different sections (sleeper displacement $2 \mathrm{~mm}$ ).

Based on the test results, when the ultimate displacement is $2 \mathrm{~mm}[7,8]$, the ballast longitudinal resistance on the subgrade is about $28.0 \mathrm{kN} /$ sleeper. There is unrecoverable plastic deformation of the ballast bed after unloading, and a higher sleeper displacement value during loading will lead to a higher ballast residual plastic deformation (Figure 10 (a)). In addition, the ballast longitudinal resistances on bridge are regionally distributed and featured obvious attenuation compared with those on the subgrade. Because of the track-bridge longitudinal interaction, a relative displacement is present between the bridge and rail under loads such as temperature. At this time, the ballast bed is continuously disturbed by the dynamic reciprocated motion of the track frame, and a larger temperature span leads to a higher disturbance. Taking testing point RF as an example, when the beam temperature changed by $15^{\circ} \mathrm{C}$, the relative displacement between the bridge and rail is about $8 \mathrm{~mm}$. 


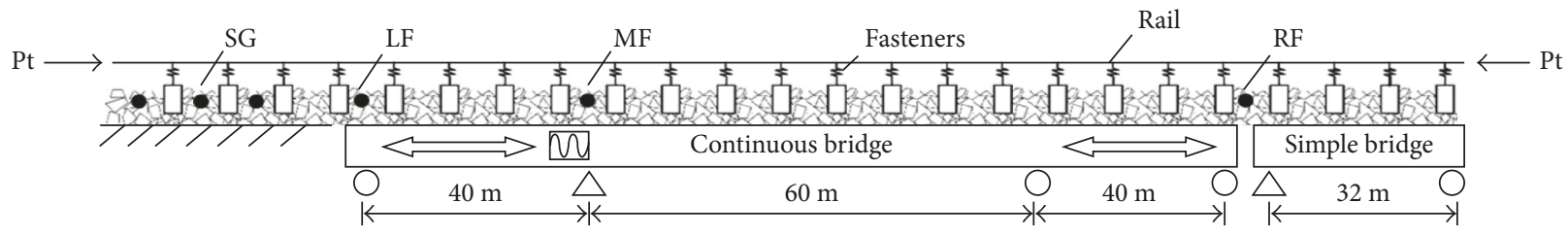

- Testing point

FIGURE 9: Outline of ballast longitudinal resistance testing.

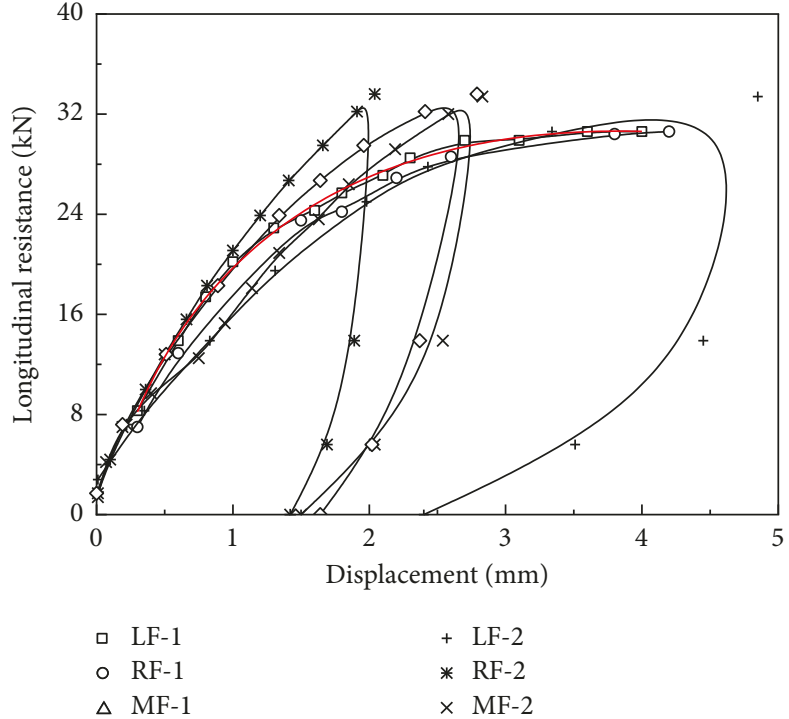

(a)

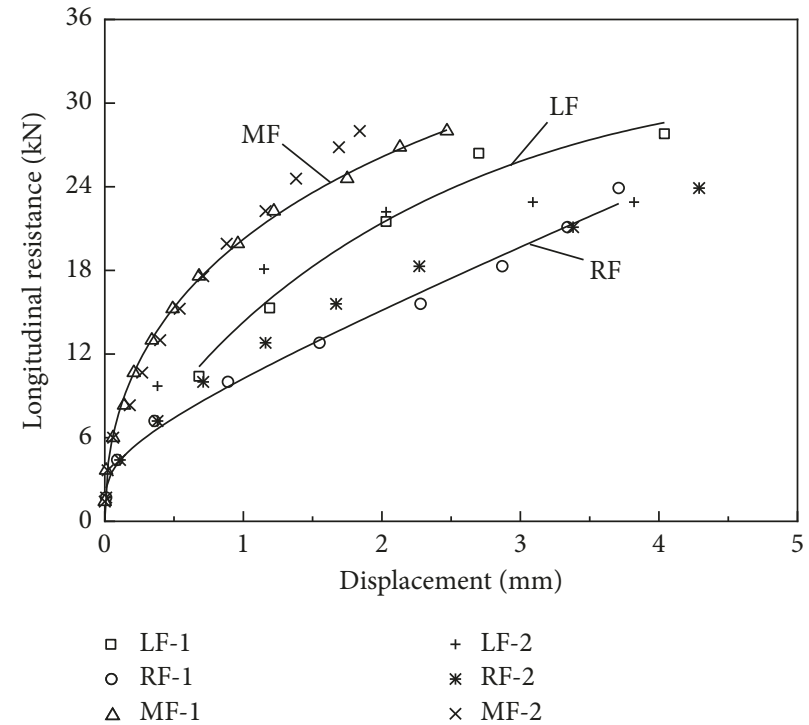

(b)

FIGURE 10: Ballast longitudinal resistance-displacement curves (a) on the subgrade and (b) on the bridge.

TABLE 2: Tested ballast longitudinal resistances.

\begin{tabular}{lcccc}
\hline $\begin{array}{l}\text { Position of testing } \\
\text { point }\end{array}$ & $\begin{array}{c}\text { Testing } \\
\text { point }\end{array}$ & $\begin{array}{c}\text { Longitudinal resistance } \\
(\mathrm{kN} / \text { sleeper })\end{array}$ & $\begin{array}{c}\text { Mean resistance } \\
(\mathrm{kN} / \text { sleeper })\end{array}$ & Notes \\
\hline \multirow{4}{*}{ On subgrade } & SG-1 & 26.6 & 28.0 & - \\
& SG-2 & 27.6 & 21.7 & Temperature span $72 \mathrm{~m}$ \\
& SG-2 & 29.8 & 15.8 & Temperature span $100 \mathrm{~m}$ \\
On bridge & LF-1 & 21.3 & & Above the fixed pier of the continuous beam \\
& LF-2 & 21.1 & 27.4 & bridge \\
\hline
\end{tabular}

Under the long-term expansion-contraction of the beam body, compared with testing point RF, the ballast longitudinal resistance degenerates obviously, dropping to only $15.8 \mathrm{kN} /$ sleeper. For those testing points (LF, MF) of the ballast bed with low disturbance, the structure of the ballast bed is maintained well, and the longitudinal resistance decreased within a narrow range. Therefore, for CWR tracks on long-span bridges under long-term cyclic loading, the ballast beds are always subject to dynamic reciprocated disturbance and tend toward looseness and the ballast resistance will degenerate.

\section{Conclusions}

A series of model tests investigated the dynamic behavior and stabilization mechanism of a granular ballast bed under a cyclic longitudinal reciprocated loading. The ballast longitudinal resistance-displacement hysteretic curves under 
cyclic loading were obtained. The longitudinal bearing and force transmission performance of the granular ballast bed were also captured, which could provide reference for further understanding and research on long-term service performance of a granular ballast bed, and could be considered as a foundation for an in-depth understanding of the stress deformation mechanism of CWR tracks. In addition, from a more practical point of view, the influence of train loads and tamping on ballast behavior has yet to be clarified.

Based on the research results, the following conclusions are summarized as follows:

(1) The unloading and loading curves of granular ballast beds do not coincide with each other under cyclic loading, forming a closed, antisymmetrically distributed hysteretic curve, indicating a significant energy consumption phenomenon. Granular ballast beds display cyclic degeneration during dynamic cyclic disturbance, including longitudinal bearing capacity degeneration and residual deformation increase.

(2) After ballast beds are disturbed under longitudinal reciprocated loading, the ballast longitudinal resistance degenerates, and this degeneration has a close relationship with the displacement amplitude under cyclic disturbance. When the displacement amplitude under cyclic disturbance is low, the ballast longitudinal resistance decreases within a narrow range; when the disturbance amplitude is high, the integrity of the ballast bed will decline, causing plastic flow of the ballast at the sleeper ends and cribs, and the ballast longitudinal resistance demonstrates significant elastic-plastic degeneration.

(3) Ballast beds always tend toward looseness due to the longitudinal track-bridge longitudinal interaction and continuous disturbance from the dynamic reciprocated motion of track frame. The ballast longitudinal resistances on bridge are distributed regionally and the evolution trend of the ballast resistance degenerates.

(4) For ballast beds under long-term service, the attenuation of resistance transference capacity under dynamic reciprocated disturbance loading should be fully considered in order to avoid a decrease in line stability caused by degeneration of ballast longitudinal resistances.

\section{Conflicts of Interest}

The authors declare that they have no conflicts of interest.

\section{Acknowledgments}

The authors thank the National Natural Science Foundation of China (nos. 51425804 and U1334203) and the Doctoral Innovation Fund of Southwest Jiaotong University (2014310016) for their funding support.

\section{References}

[1] E. Tutumluer, H. Huang, Y. M. A. Hashash, and J. Ghaboussi, "Discrete element modeling of railroad ballast settlement," in Proceedings of 2007 AREMA Annual Conference, Chicago, IL, USA, September 2007.

[2] B. Indraratna and W. Salim, Mechanics of Ballasted Rail Tracks: A Geotechnical Perspective, Taylor and Francis/Balkema, London, UK, 2005.

[3] W. L. Lim, Mechanics of Railway Ballast Behaviour, University of Nottingham, Nottingham, UK, 2004.

[4] H. Huang and E. Tutumluer, "Discrete element modeling for fouled railroad ballast," Construction and Building Materials, vol. 25, no. 8, pp. 3306-3312, 2011.

[5] W. F. Anderson and P. Fair, "Behaviour of railroad ballast under monotonic and cyclic loading," Journal of Geotechnical and Geoenvironmental Engineering, vol. 134, no. 3, pp. 316327, 2008.

[6] G. Samavedam and A. Kish, "Continuous welded rail track buckling safety assurance through field measurements of track resistance and rail force," Transportation Research Record, vol. 33, no. 1289, pp. 39-52, 1995.

[7] C. Esveld, Modern Railway Track, MRT Press, Netherlands, 2001.

[8] A. Kish and G. Samavedam, "Dynamic buckling of continuous welded rail track: theory, tests, and safety concepts," Transportation Research Record, vol. 29, no. 1289, pp. 23-38, 1991.

[9] A. De Iorio, M. Grasso, F. Penta, G. P. Pucillo, S. Rossi, and M. Testa, "On the ballast-sleeper interaction in the longitudinal and lateral directions," Proceedings of the Institution of Mechanical Engineers, Part F: Journal of Rail and Rapid Transit, pp. 1-12, 2017.

[10] M. Esmaeili, R. Nouri, and K. Yousefian, "Experimental comparison of the lateral resistance of tracks with steel slag ballast and limestone ballast materials," Proceedings of the Institution of Mechanical Engineers, Part F: Journal of Rail and Rapid Transit, vol. 231, no. 2, pp. 175-184, 2017.

[11] A. Kish and M. Coltman, "New techniques for rail longitudinal force measurement and rail restraint capacity evaluations," Area Bulletin, no. 727, pp. 236-240, 1990.

[12] P. Ruge and C. Birk, "Longitudinal forces in continuously welded rails on bridge decks due to nonlinear track bridge interaction," Computers and Structures, vol. 85, no. 7-8, pp. 458-475, 2007.

[13] J. Xiao, H. Liu, J. Xu, P. Wang, G. Liu, and R. Chen, "Longitudinal resistance performance of granular ballast beds under cyclic symmetric displacement loading," Journal of Zhejiang University-SCIENCE A, vol. 18, no. 8, pp. 648-659, 2017.

[14] O. Kerokoski, "Determination of longitudinal and transverse railway track resistance," in Proceedings of the 2010 IEEE/ASME Joint Rail Conference, Urbana, IL, USA, April 2010.

[15] Union Internationale des Chemins de fer, Track/Bridge Interaction Recommendations for Calculations, UIC 774-3E, International Union of Railways, Paris, France, 2001.

[16] T. Rauert, H. Bigelow, B. Hoffmeister, and M. Feldmann, "On the prediction of the interaction effect caused by continuous ballast on filler beam railway bridges by experimentally supported numerical studies," Engineering Structures, vol. 32, no. 12, pp. 3981-3988, 2010.

[17] L. M. Le Pen and W. Powrie, "Contribution of base, crib and shoulder ballast to the lateral sliding resistance of railway 
track: a geotechnical perspective," Proceedings of the Institution of Mechanical Engineers Part F: Journal of Rail and Rapid Transit, vol. 225, no. 2, pp. 113-128, 2011.

[18] L. M. Le Pen, A. R. Bhandari, and W. Powrie, "Sleeper end resistance of ballasted railway tracks," Journal of Geotechnical and Geoenvironmental Engineering, vol. 140, no. 5, p. 04014004, 2014.

[19] Y. Koike, T. Nakamura, K. Hayano, and Y. Momoya, "Numerical method for evaluating the lateral resistance of sleepers in ballasted tracks," Soils and Foundations, vol. 54, no. 3, pp. 502-514, 2014.

[20] B. Indraratna, P. K. Thakur, and J. S. Vinod, "Experimental and numerical study of railway ballast behavior under cyclic loading," International Journal of Geomechanics, vol. 10, no. 4, pp. 136-144, 2010.

[21] A. Mamou, W. Powrie, J. A. Priest, and C. Clayton, "The effects of drainage on the behaviour of railway track foundation materials during cyclic loading," Geotechnique, vol. 68, no. 4, pp. 1-10, 2017.

[22] G. Q. Jing, Railway Ballast Bed, China Railway Publishing House, Beijing, China, 2012.

[23] The Ministry of Railways of the People's Republic of China, Railway Ballast (TB/T 2140-2008), Railway Industry Standard of the People's Republic of China, Beijing, China, 2008.

[24] The Ministry of Railways of the People's Republic of China, Code For Design of High-Speed Railway in China (TB 106212014), Railway Industry Standard of the People's Republic of China, Beijing, China, 2014.

[25] A. Riccio, R. Cristiano, G. Mezzacapo, M. Zarrelli, and C. Toscano, "Experimental investigation of delamination growth in composite laminates under a compressive load," Advances in Materials Science and Engineering, vol. 2017, Article ID 3431093, 17 pages, 2017.

[26] B. Aursudkij, A Laboratory Study of Railway Ballast Behaviour under Traffic Loading and Tamping Maintenance, Ph.D. thesis, University of Nottingham, Nottingham, UK, 2007.

[27] E. Tutumluer, H. Huang, Y. M. A. Hashash, and J. Ghaboussi, "Aggregate shape effects on ballast tamping and railroad track lateral stability," in Proceedings of AREMA Annual Conference, Louisville, KY, USA, September 2006. 


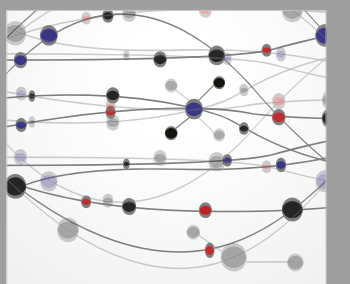

The Scientific World Journal
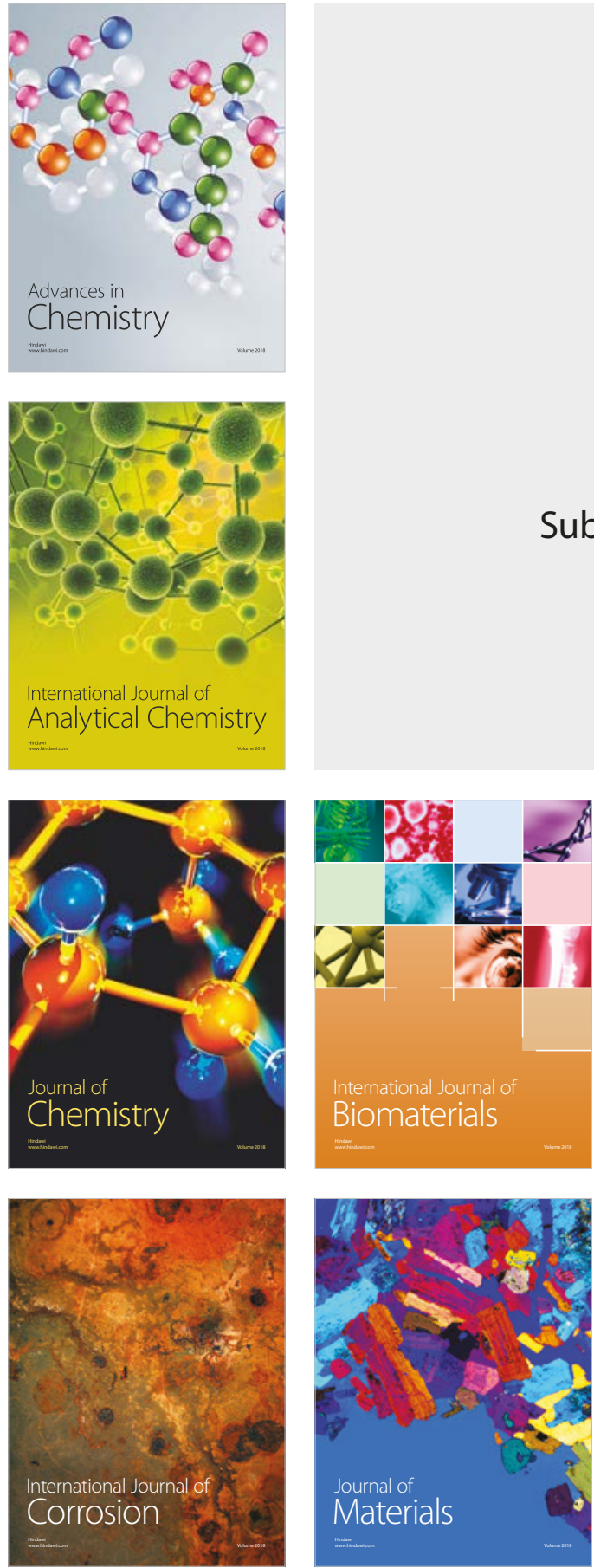

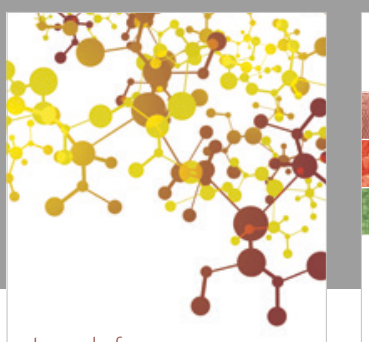

Journal of

Applied Chemistry
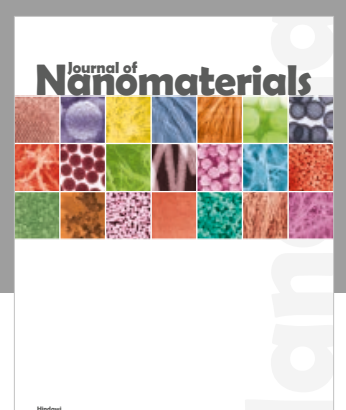

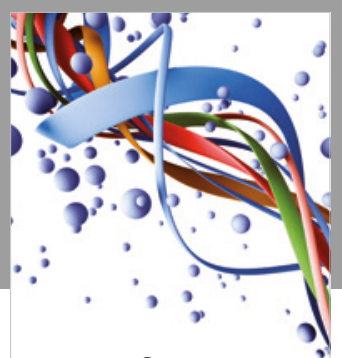

Scientifica

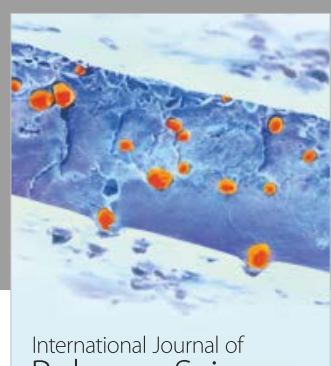

Polymer Science

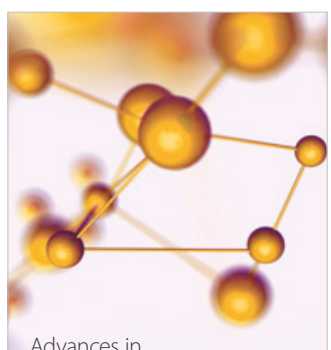

Physical Chemistry
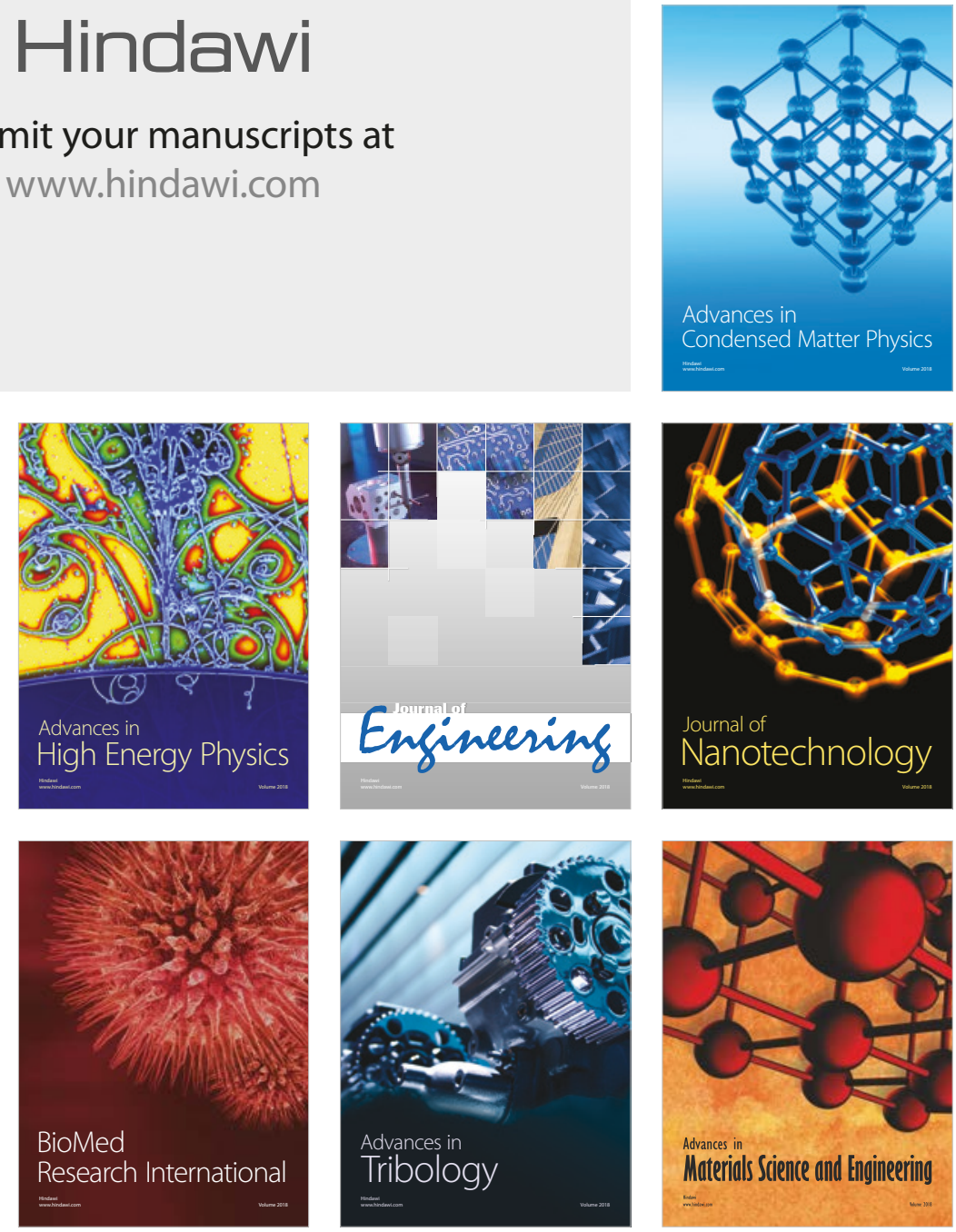